Vol. 4, No. 1, 2018

Baltic Journal of Economic Studies

DOI: https://doi.org/10.30525/2256-0742/2018-4-1-311-318

\title{
DEVELOPMENT OF A MODEL OF DIGITAL RESEARCH UNIVERSITIES
}

\author{
Maksym Sitnicki ${ }^{1}$ \\ Taras Shevchenko National University of Kyiv, Ukraine
}

\begin{abstract}
The aim of the article is studying modern trends in digital development and developing a universal model of digital research universities. The methodology of the research is based on the use of methods: analysis and comparison for the study of scientific thought in the field of the introduction of digital technologies in the activities of research universities of systematization in the process of singling out the spheres of use of digital technologies in the activities of research universities; graphics for developing a model of digital research universities. The research results are manifested in the generalized development of global scientific thought for the period of 2011-2018. On the use of digital technologies in research universities in the United States, Britain, Germany, Canada, Australia, New Zealand, Ireland, Italy, South Africa, Brazil, Ireland, Finland, India. The results identify the current trends in global scientific research on the introduction of digital technologies concerning issues: the effectiveness of the formation of students' own curriculum; digitization of scientific information; the emergence and development of digital scholarships in scientific libraries; studying the correlation between the number of downloaded articles from the digital space and the number of new articles being written; a reappraisal of the revolutionary role of digital technologies in the social sciences; the rationale for American scientists to create a new model that provides access to the academic platform for a global society; intensification of the exchange of digital data; analysis and comparison of advantages and disadvantages of digital storages; search for new components of research tools based on the study of digital methods; the global development of digital technologies and the enhancement of the effectiveness of digital research cooperation; the widespread use of the Internet and other digital resources on the activities of research universities to improve the quality and semantic consistency of metadata, allowing to identify the digital preservation of research material. The proposed author's definition of "digital research university" harmonized the scientific categorical apparatus in accordance with modern trends in the development of digital technologies in research universities. The practical implications of introducing this category in widespread use will be reflected in the rethinking of the role of research universities and the search for new forms of introducing digital technologies. The difference between the proposed category and the term "digital university", already used in scientific consumption, is the wider coverage of the characteristics of research activities of research universities using digital technologies. The systematization of the use of digital technologies in research universities has made it possible to identify ten main areas: automation of the management systems of research universities digitizing literary sources in scientific libraries; automation of the educational process; online teaching; conducting final control; repository of diploma and doctoral thesis; student, teaching and research social networks; implementation of joint research online in digital networks; exchange of scientific data. Identified spheres form a system of digital means for the educational and scientific activities of research universities. Their characteristics allow highlighting the effects that arise in the process of introducing digital technologies in research universities. A three-level model of digital research universities has been developed. It combines nine basic elements: electronic portfolio; digital depository; digital training of teachers and researchers; an online platform for teaching; R\&D market; research framing; virtual social networks; digital research networks; evaluation of research quality. The proposed three levels of the model reveal the basic role of its elements for the digital development of research universities and provide: the necessary internal infrastructure; maximizing the effects of using digital technologies; international subjectivization of research universities. The author's definition of each element of the developed model is provided, disclosed their digital purpose, and enriched the categorical apparatus. The practical significance of the developed model is ensuring that the maximum is obtained from the use by the research universities of the digital technologies of the present, and waiting for humanity in a strategic future.
\end{abstract}

Key words: model of digital research universities, areas of use of digital technologies, modern trends in digital research, research universities.

JEL Classification: F02, M15, C59, B22

Corresponding author:

${ }^{1}$ Management of Innovation and Investment Activity Department, Taras Shevchenko National University of Kyiv.

E-mail: maksym.sitnicki@ukr.net 


\section{Introduction}

Traditional forms of research universities are already working at the limit of their technological capabilities. This can be traced on an equal basis, both in educational and research activities. Internet technologies and the ever-increasing opportunities for the digitization of knowledge make it possible to effectively study not within the walls of universities. Knowledge transfer technologies have received new digital forms, and now anyone can get a university education from online sources. Of course, the high role of the professor at the university will not be replaced by robotics and the need for live communication, consultations, and discussions will remain relevant. Truth is born in the process of reflection, collective thinking, and creative atmosphere. These conditions are provided by classical research universities. But we should not exclude the appearance of such machines that will replace these supercomplex human relations and bring human processes of learning, thinking, and scientific search closer to them, and even surpass them.

Considering this novelty of the research topic, the modern trends in the transition to the digital space of all managerial processes are modernized and are relevant in view of the important research task - to increase the efficiency of research universities in the digitalization era.

The aim of the research is studying the current trends in digital development and the development of a universal model of digital research universities. To achieve the aim in the work, the following tasks are set:

- to analyse literary sources in order to identify current scientific trends in the use of digital technologies by research universities;

- granting of the author's definition of the economic category "digital research university";

- to systematize and characterize the use of digital technologies in research universities;

- to develop and characterize the model of digital research universities that will correspond to the technologies and processes that humanity expects in the strategic future.

To solve the tasks and achieve the research aim, the following scientific methods are used: analysis, systematization, comparison, graphic.

\section{Literature review}

The conceptual study (Liu, Wang \& Cheng, 2011) shows how in the framework of global higher education world-class universities are considered as elite research universities. They play an important role in the development of human resources and the creation of new scientific information in the context of a knowledge-based economy. In this study (Lynch \& Carleton, 2012), the reasonably important thesis is that the future of scientific libraries will be shaped by the wider development of research universities in the fields of digital creation, exchange, dissemination, and translation of knowledge. The book is published in Great Britain by authoritative scientists (Goodfellow \& Lea, 2013). The authors describe the category "digital university"; study the issue of digital literacy in universities; the value of digital texts; the practice of academic literacy around Twitter; lead effective practices for the dissemination of literacy, e-learning in a digital university; characterized digital cognitive literacy; investigate how digital literary knowledge affects the scientists and students' behaviour; propose new approaches to the creation of digital content and cooperation. In work (Jagdish, Kruti \& Ajit 2013) the effect of granting to 50th Indian universities of electronic access to national and international scientific journals from the consortium of digital libraries is investigated. A strong positive correlation is found between the number of articles downloaded by these 50 universities from available digital resources and research publications that were published after receiving this access. Research (Dutton, 2013) aims to help translate the diversity of perspectives that digitalization of the social sciences can bring. The further dissemination of digital research makes it increasingly important to strengthen the role of social sciences in interdisciplinary studies at the global level.

Using digital tools and techniques in archaeological research (Agbe-Davies, Galle, Hauser, \& Neiman, 2014), digital technology has revolutionized the rethinking of digital archaeological data. The authors conclude that digital technology was an underrated resource for practice and learning.

The study is devoted to the development of American research universities, constantly dominating the world rankings (Crow \& Dabars, 2015). The authors justify the need to create a new model that provides access to the academic platform to a wide range of representatives of society. The issue of the exchange of digital research data is considered in the work (Bishoff \& Johnston, 2015). It is established that this practice is becoming more common, taking into account the requirements of publishers of journals, global scientific associations, and public expectations about the creation of more interdisciplinary research environments. The development of digital technologies in Germanyis shown in the work (Roberta, Tim \& Silke, 2015). Authors are invited to review three projects focused on the use of digital tools implemented by an interdisciplinary team of scientists based on the Goethe Universität Frankfurt. This study analyses, compares, and demonstrates the shortcomings of digital storage in six Arab universities: Alexandria University, Damascus University, Khartoum University, King Saud University, Petrol and Minerals University and Nayef University of the security sciences. This work (Shin \& Lee, 2015) focuses on researching universities as a part of Korea's national research system. Digital support for the economic development of the 
country is due to the innovative development of Korean research universities.

The study argues that digital methods are increasingly becoming key components of research tools (Sparks, Collins, \& Kearns, 2016). There are three special issues that are crucial for researchers working with digital methodologies: the ethical consequences of procedural violations, institutional responses in a neo-liberal university and the well-being of researchers. The authors insist that researchers continue to move the boundaries through digital research, but suggest that this should be done in a weighted way, given the immanent potential of digital disturbances. The possibilities of digital technologies are deeply analysed in the study (Hargittai, \& Sandvig, 2016). The field of digital technologies offers both new research methods and new objects of study. Since the digital environment is constantly evolving, researchers sometimes have to improvise, change their plans, and adapt.

Research (Canhoto, Quinton, Jackson, \& Dibb, 2016) analyses the process of digital research collaboration between research universities, industry, and scientists in the context of implementing digital research projects. The authors proposed five practical principles for the successful development of joint research projects in the context of university cooperation in the UK. This work (Tsatsou, 2016) shows a qualitative study of the use of digital tools, resources, and services by researchers in the UK. The author shows the use of digital research tools at the design stage of research to collect data and disseminate the results. Also, the complexity and multiplicity of digital tools, resources and services used in research are assessed. The paper concludes that there are certain commonalities and differences in the practice of researchers with digital technologies, and this practice largely depends on the experience of researchers in conjunction with the relevant disciplinary traditions and etiquette.

Research (Grimaldi, Cavagnero, \& Gallina, 2016) focuses on the perception of postmodern generations of information retrieval in the digital space. The survey was conducted among 151 students of the first year of teaching at the Faculty of Education of Turin University (2014-15). The activity on the Internet and the perception of the economic value that respondents attribute to the information they find on the Internet every day are analysed. In this study (Barana, Bogino, Fioravera, Marchisio, Rabellino, 2016), the digital project “Orient@mente”, developed by the University of Turin from the 2014/2015 academic year, is analysed. The concept of the project is supporting students in the formation of their own curriculum at the university. Students' feedback shows a high appreciation for these innovative teaching methods and digital devices for studying mathematics and other disciplines. In the future, the University of Turin is interested in expanding similar technologies with a focus on other courses.
The issue of open education with access to social networks is explored in the work (Fan \& Liu, 2016). It shows how universities, through an open access to knowledge, promote the development of many academic values through greater openness to society. Using the example of a study of start-ups, the scale of the study of the digital economy in Poland is shown (Skala, 2016). The study presents the first survey in Polish companies related to the digital economy.

The study (Primary Research, 2016) provides detailed data on how faculties evaluate the efforts of their university for reporting, the publication of research results and other activities in the digital environment. The survey data is based on a survey of more than 500 scientists from more than 50 leading research universities in the US, Canada, Britain, Australia, New Zealand, and Ireland. In work (Koopman, \& de Jager, 2016), the features of storing and managing digital data on the example of institutions in South Africa have been explored. It turned out that, although some researchers were already engaged in digital archival data in storage facilities, neither researchers nor universities carried out systematic management of research data.

This book (Stensaker, Bilbow, Breslow, \& Van Der Vaart, 2017) highlights various approaches and concrete examples of how world-class research universities from around the world work to improve teaching and learning. Broad university initiatives and approaches in the field of introducing digital technologies are shown. The study (Firima Zona, Ridwan, \& Uli Agustina, 2017) examines in detail the impact of widespread use of the Internet and other digital resources on reading habits and gave practical recommendations for improving the abilities of readers in the digital age. In work (Hladik, 2017), the growing use of digital technologies in scientific work and communication in a university environment is explored. A particular attention is paid to the concept of the code of knowledge as a literary technology and the role of digital technologies in the humanities.

Digital technologies of an online class are investigated in work (Boria Sax, 2017). It is revealed that the electronic portfolio of educational material, the student communities are more interested, can continue to develop and expand independently even after the end of the training period. A classification of digital funds is carried out, using both statistical significance and the effects of differences among 902 universities in 54 countries (Leydesdorff, Bornmann, \& Mingers, 2017). The authors focus mainly on Great Britain, Germany, and Brazil. Considered (LeBard, Brynn Hibbert, \& Quinnell, 2017), how new digital technologies affect the cultivation of university science. The authors introduce the concept of the electronic laboratory notebook computer (ELN), which is used in the research environment, and describe how they implemented it as a tool to provide students with a basic research experience. 
Research (Fierro, Cardona Arbelaez \& Gavilanez, 2017) reveals new horizons of international education in the digital age, has undergone significant changes. Digital platforms have greatly facilitated students' access to academic information. The importance of digital marketing and its components in international education for improving business practices is grounded.

Research (Cox, 2017) shows new scientific needs, global events, and shifts, require a wider range of interaction of librarians with researchers and contradict the previous organizational structures. The paper shows the special circumstances at the National University of Ireland Galway, which formed a system for stimulating the work of the library staff. These include: the emergence of digital scholarships, the convenient technology of the research building, investing in digital archives and updating the digital strategy. Finland's experience in implementing information systems and harmonizing obsolete data models has been studied in the work (Remes, Alonen, Maltusch, Hällström \& Westman, 2017). It is established that the more investing in open science and research, the more it becomes necessary that the metadata that allows identifying the digital preservation of research material be qualitative and semantically consistent.

In work (Yan, \& Zhang, 2018), the scientific reputation of ResearchGate is analysed as one of the largest active academic sites of social networks in the world. This study collects RG user data from 61 US research universities at different levels of research, classified by Carnegie Institutes of Higher Education, to examine the impact of institutional differences on RG's reputation. The results confirm that RG is a scientific-oriented scientific social networking site, closely and realistically reflects the level of research activities of institutions. With the increase in the level of research activity of the university, its affiliated
RG users tend to have larger RG scores, more publications and citations, as well as more views and followers, while the average number of readings of their publications and words is usually lower.

\section{Results}

\section{Definition}

Based on the research conducted by the authoritative scientists in the field of digital content of research universities, it is established that the term "digital university" was widely accepted and characterized (Goodfellow \& Lea, 2013, p. 2). The main emphasis is placed on the fact that, in the face of broad technological and structural changes, it became necessary to combine various forms of social practice around learning and technology.

Along with this, scientific activity has not found its full expression in this category. Considering this, there is a need to introduce the economic category "digital research university" into scientific circulation, which will fully allow expressing the purposes and activities of these institutions. So, let us describe and characterize the author's definition.

Digital research university is a research and educational institution that carries out its activity on the basis of automation of educational and research processes and provides a complete digital cycle for the creation, codification, archiving, storage, exchange, retrieval, and broadcasting of scientific and educational information that was created as a result of research activities.

Spheres of use of digital technologies in research universities

Based on the above definition of a digital research university, let's systematize the use of digital technologies in research universities, Table 1.

Table 1

Areas of use of digital technologies in research universities

\begin{tabular}{|c|c|c|}
\hline № & Areas & Effects \\
\hline 1 & $\begin{array}{l}\text { Automation of control } \\
\text { systems of research } \\
\text { universities }\end{array}$ & $\begin{array}{l}\text { Optimization and efficiency improvement: } \\
\text { - accounting and attestation of personnel; } \\
\text { - financial management and reporting; } \\
\text { - control over fixed assets; } \\
\text { - accounting for applicants, students, and graduates; } \\
\text { - security systems of the university. }\end{array}$ \\
\hline 2 & $\begin{array}{c}\text { Digitization of literary } \\
\text { sources in scientific libraries }\end{array}$ & $\begin{array}{l}\text { - improving the efficiency of searching for necessary literature; } \\
\text { - providing the ability to view the sources of an unlimited number of users; } \\
\text { - preservation (archiving) of valuable copies in electronic form. }\end{array}$ \\
\hline 3 & $\begin{array}{l}\text { Automation of educational } \\
\text { process }\end{array}$ & $\begin{array}{l}\text { - opportunity for students to form their own curriculum independently; } \\
\text { - convenience in scheduling classes and consultations; } \\
\text { - comfort of the evaluation process and the confidentiality of the presentation of the awarded points. }\end{array}$ \\
\hline 4 & Online Teaching & $\begin{array}{l}\text { - expansion of the audience of listeners, both in the middle of university networks and providing } \\
\text { wide access in the global environment; } \\
\text { - wide possibilities of attraction to the educational process of auxiliary methodical materials and } \\
\text { developments; } \\
\text { - possibility of introducing paid courses for all those interested in the external environment, the } \\
\text { account of listeners. }\end{array}$ \\
\hline
\end{tabular}


Vol. 4, No. 1, 2018

End of Table 1

\begin{tabular}{|c|c|l|}
\hline 6 & $\begin{array}{c}\text { Conducting the final } \\
\text { control (testing, interview, } \\
\text { compilation of intermediate } \\
\text { control works, etc.) }\end{array}$ & $\begin{array}{l}\text { - increase the flexibility of the educational process; } \\
\text { - automation of work verification and evaluation of results; } \\
\text { - standardized tasks, equal conditions for students; } \\
\text { - optimization of working hours of research university staff. }\end{array}$ \\
\hline 7 & $\begin{array}{c}\text { Diploma and doctoral thesis } \\
\text { repository }\end{array}$ & $\begin{array}{l}\text { - automatic verification of academic virtue; } \\
\text { - systematization of scientific research directions; } \\
\text { - the possibility of providing global online access to scientists from other universities or academic } \\
\text { institutions. }\end{array}$ \\
\hline 8 & $\begin{array}{c}\text { Student, teaching and } \\
\text { research social networks }\end{array}$ & $\begin{array}{l}\text { - operational communication; } \\
\text { - search for partners for educational and scientific interests; } \\
\text { - formation of joint teams and teams. }\end{array}$ \\
\hline 9 & $\begin{array}{c}\text { Carrying out joint research } \\
\text { online in digital networks }\end{array}$ & $\begin{array}{l}\text { - optimization of time for interpersonal communication; } \\
\text { - joint writing and editing of scientific texts; } \\
\text { - operative analysis and discussion of the results of laboratory tests and experiments; } \\
\text { - setting up professional software. }\end{array}$ \\
\hline 10 & Exchange of scientific data & $\begin{array}{l}\text { - online seminars, conferences, webinars; } \\
\text { - online publication of scientific research results; } \\
\text { - general bases of statistical and scientific information. }\end{array}$ \\
\hline
\end{tabular}

Source: developed by the author

\section{Model of digital research universities}

Let's develop a model of digital research universities that will correspond to technologies and processes that are relevant today and are waiting for humanity in a strategic future.

A three-level model is developed, Fig. 1, which clearly illustrates processes and infrastructure units, uses digital technologies in research universities, and is focused on providing not only modern needs but also hypothetical needs arising in the strategic future. Let us characterize the components of this three-level model.

1. E-portfolio is a set of digitized educational and research materials of scientific and pedagogical staff of research universities, virtually displays the full set of tools and methods used in the training and research activities of employees.

2. Digital depository is the basis of digitized educational and scientific literature that is contained in virtual archives of scientific libraries of research universities and databases.

3. Digital training of teachers and researchers is a process of development that provides for the systematic upgrading of the scientific and pedagogical staff of research universities for the free use of digital technologies in educational and scientific activities.

Characterized elements represent the first level of the model reflecting the necessary internal infrastructure and processes in research universities to enable the introduction of digital technologies.

4. Online teaching platforms is the availability of own and use of public platforms that serve as a means of digital communication between teachers of academic courses and training programs and students and volunteers.

5. R\&D market is an infrastructure that provides effective communication between performers of

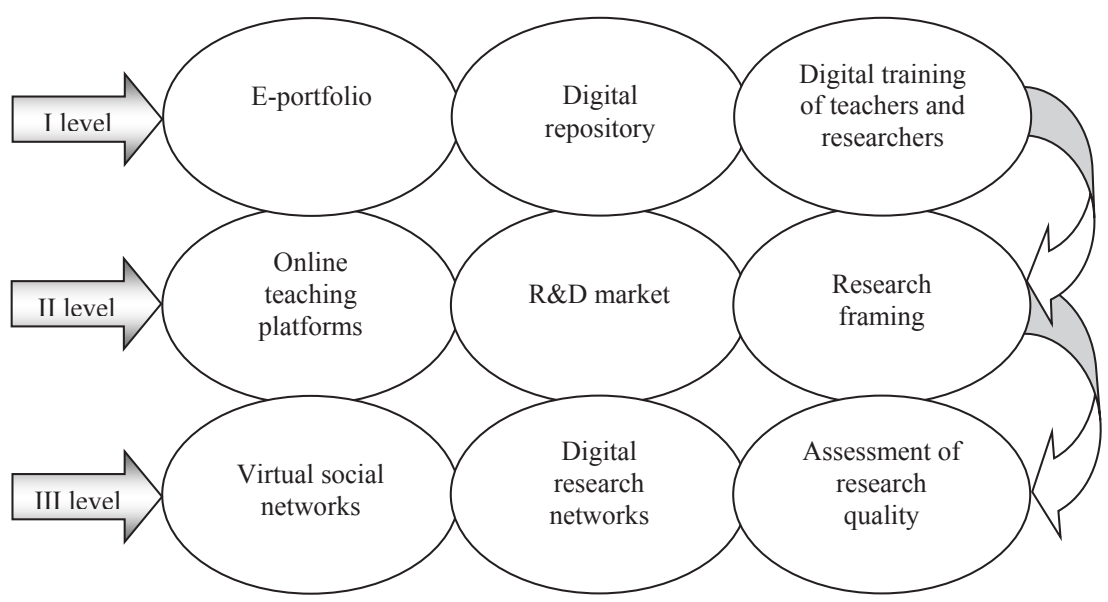

Fig. 1. Model of digital research universities

Source: developed by the author 
scientific, research, theoretical and experimental research works and customers, buyers, and investors.

6. Research framing is the process of mental classification by scientists of clusters of digital research information and ideas in the modern discourse of digital technologies, helps scientists to perceive development trends and use new digital technologies.

Elements that form the basis of the second level of the model contribute to maximizing the benefits and effects from the use of digital technologies in the educational and scientific activities of research universities and provide the process of rethinking and setting new tasks for digital modernization.

7. Virtual social networks is a digital infrastructure that provides an instant communication process between teachers and scientists with the purpose of exchanging ideas and forming communities that realize joint thoughts.

8. Digital research networks are territorial, interstate, and intercontinental scientific research associations in the digital space, ensuring the exchange of experimental data and results of laboratory research and implementation of joint scientific projects.

9. Assessment of research quality is a system that provides assessments of the global significance of scientific research results using the tools of digital space.

The given elements of the third level of the model contribute to the international subjectivization of research universities and the development of science through global research activities in joint transboundary networks and consortia.

The overall balance of the developed model is ensured by the close interaction of its elements. The digital space gives unlimited possibilities of the flexibility of these elements and maximization of effects from their use by research universities. The model is universal and developed for the implementation by research universities, both elite world class, and those that seek to obtain such a status in a global environment.

\section{Conclusions}

Having studied the development of scientific thought for the period of 2011-2018 regarding digital technologies, it has been established by the example of the research universities of the USA, Great Britain, Germany, Canada, Australia, New Zealand, Ireland, Italy, South Africa, Brazil, Ireland, Finland, India, that the current trends in digital research of scientists are:

- the effectiveness of students forming their own curriculum in research universities;

- digitalization of the archiving of scientific information in research universities;

- emergence and development of digital scholarships in research libraries of research universities;

- rationale for the need to identify elite research universities;
- study of the correlation between the number of articles downloaded from the digital space and the number of new articles written in research universities;

- reassessment of the revolutionary role of digital technologies in the rethinking of digital archaeological data is being studied by research universities;

- justification by American scientists of the need to create a new model that provides access to the academic platform for a wide range of representatives of the global society;

- issue of intensification of the exchange of digital data between research universities and the role of scientific social networks in this;

- analysis and comparison of advantages and disadvantages of digital storages in research universities; - search for new components of research tools based on the study of digital methods;

- effective ways of developing digital technologies in research universities should be based on a balanced approach and risk analysis;

- expanding and enhancing the effectiveness of digital research cooperation between research universities in the world;

- impact of widespread use of the Internet and other digital resources on the activities of research universities; - improving the quality and semantic consistency of metadata, allowing to identify the digital preservation of research material.

In fact, the above-mentioned areas of digital development in research universities are a priority in the scientific research of scientists from all over the world.

The proposed author's definition of the economic category "digital research university" harmonizes the scientific categorical apparatus in accordance with modern trends in the development of digital technologies in research universities. Its difference from the term "digital university", already used in scientific consumption, consists in a wider coverage of the characteristics of scientific activity of research universities using digital technologies.

The systematization of the use of digital technologies in research universities has made it possible to identify ten main areas: automation of the management systems of research universities digitizing literary sources in scientific libraries; automation of the educational process; online teaching; conducting final control; repository of diploma and doctoral thesis; student, teaching and research social networks; implementation of joint research online in digital networks; exchange of scientific data. It is established that these spheres form a system of digital means for the educational and scientific activities of research universities. Their characteristics allowed us to highlight the effects that arise in the process of introducing digital technologies in research universities.

The developed model of digital research universities has united nine basic elements: electronic portfolio; digital 
depository; digital training of teachers and researchers; an online platform for teaching; R\&D market; research framing; virtual social networks; digital research networks; evaluation of research quality. This model is presented in a three-level form. The proposed three levels reveal the main role of the model elements for the digital development of research universities and provide:

- necessary internal infrastructure and processes to enable the introduction of digital technologies;

- maximizing the benefits and effects of using digital technologies in the educational and research activities of research universities and providing a process of rethinking and posing new tasks of digital modernization;
- international subjectivization of research universities and the development of science through global research activities in joint transboundary networks.

The characteristics of the elements of the developed model, in fact, allow providing the author's definitions of each of them, disclose their digital purposes, and enrich the categorical apparatus. The practical significance of the developed model is designed to provide the maximum from the use of digital technologies present and waiting for humanity in a strategic future. It is precisely the appraisal of existing and identification of new directions for the digital development of research universities that will be devoted to our further scientific research in this direction.

\section{References:}

Abd Allah Mohamed Abd Allah aalYateem, Nawaf Bandr Bn Hameed. (2015). Digital Repositories in the Arab Universities: A Comparative Analytical Study, Procedia Computer Science, 65: 768-777. DOI: https://doi.org/10.1016/j.procs.2015.09.022

Agbe-Davies, A.S., Galle, J.E., Hauser, M.W., \& Neiman, F.D. (2014). Teaching with digital archaeological data: A research archive in the university classroom. Journal of Archaeological Method and Theory, 21(4): 837-861. DOI: 10.1007/s10816-013-9178-3

Barana, A., Bogino, A., Fioravera, M., Marchisio, M, Rabellino, S. (2016). Digital Support for University Guidance and Improvement of Study Results, Procedia - Social and Behavioral Sciences, 228: 547-552. DOI: https://doi.org/10.1016/j.sbspro.2016.07.084.

Bishoff, C., \& Johnston, L. (2015). Approaches to Data Sharing: An Analysis of NSF Data Management Plans from a Large Research University. Journal of Librarianship \& Scholarly Communication, 3(2): 1-27. DOI: 10.7710/21623309.1231

Canhoto, A.I., Quinton, S., Jackson, P., \& Dibb, S. (2016). The co-production of value in digital, university-industry R\&D collaborative projects. Industrial Marketing Management, 56: 86-96.DOI: 10.1016/j.indmarman.2016.03.010 Cox, J. (2017). New Directions for Academic Libraries in Research Staffing: A Case Study at National University of Ireland Galway. New Review Of Academic Librarianship, 23 (2-3): 110-124. DOI: http://dx.doi.org/10.1080/ 13614533.2017.1316748

Crow, M.M., \& Dabars, W.B. (2015). Designing the New American University. Baltimore, Maryland: Johns Hopkins University Press.

Dutton, W.H. (2013). The social shaping of digital research. International Journal of Social Research Methodology, 16(3): 177-195. DOI: 10.1080/13645579.2013.774171

Fan, W., \& Liu, Q. (2016). Open scholarship ranking of Chinese research universities. Scientometrics, 108(2): 673-691. DOI: $10.1007 / \mathrm{s} 11192-016-1983-5$

Fierro, I., Cardona arbelaez, D.A., \& Gavilanez, J. (2017). Digital marketing: a new tool for international education. Pensamiento \& Gestión, 43: 240-260. DOI: 10.14482/pege.41.9704

Firima Zona, T., Ridwan, R., \& Uli Agustina, G. (2017). Reading Habits in Digital Era: A Research on the Students in Borneo University. LLT Journal: A Journal On Language And Language Teaching, 20 (2): 147-157.

Goodfellow, R., \& Lea, M.R. (2013). Literacy in the digital university: critical perspectives on learning, scholarship, and technology. London; New York: Routledge Taylor \& Francis Group. http://oro.open.ac.uk/id/eprint/34778

Grimaldi, R., Cavagnero, S.M., \& Gallina, M.A. (2016). Use of internet and awareness of digital tracks. A research on university students. Sociologia e Ricerca Sociale, 109: 204-218.

Hargittai, E., \& Sandvig, C. (2016). Digital Research Confidential : The Secrets of Studying Behavior Online. Cambridge, MA: The MIT Press.

Hladík, R. (2017). Zdrojový kod jako literární technologie? O vyvárení faktú v digitálním výzkumu. Theory of Science, 39(1): 31-56.

Jagdish, A., Kruti J.,T., \& Ajit, K. (2013). Impact of access to e-resources through the UGC-INFONET Digital Library Consortium on research output of member universities. Current Science, 104 (3): 307-315.

Koopman, M.M., \& de Jager, K. (2016). Archiving South African digital research data: How ready are we?. South African Journal of Science, 112 (7/8): 42-48. DOI: 10.17159/sajs.2016/20150316

LeBard, R.J., Brynn Hibbert, D., \& Quinnell, R. (2017). Practice in Digital Research Spaces to Engage Students with eScience. Teaching Science: The Journal of The Australian Science Teachers Association, 63 (1), $41-48$.

Leydesdorff, L., Bornmann, L., \& Mingers, J. (2017). Statistical Significance and Effect Sizes of Differences among Research Universities at the Level of Nations and Worldwide based on the Leiden Rankings. http://arxiv.org abs/1710.11020 
Liu, N., Wang, Q. \& Cheng, Y. (2011). Paths to a World-Class University. Rotterdam: SensePublishers.

Lynch, C., \& Carleton, D.E. (2012). Lecture: Impact of Digital Scholarship on Research Libraries. Journal of Library Administration, 52 (6-7): 456-473. DOI: 10.1080/01930826.2012.707947

Primary Research, G. (2016). International Survey of Research University Faculty : Use of Institutional Digital Repositories. New York: Primary Research Group, Inc.

Remes, S., Alonen, M., Maltusch, P., Hällström, M. a., \& Westman, S. (2017). Say, “S” (as) Semantics - and Mean it! Path to Semantically Interoperable Digital Research Services. Procedia Computer Science, 106 (13th International Conference on Current Research Information Systems, CRIS2016, Communicating and Measuring Research Responsibly: Profiling, Metrics, Impact, Interoperability): 329-334. DOI:10.1016/j.procs.2017.03.032

Roberta, C., Tim, G., \& Silke, S. (2015). Digital Approaches to Historical Semantics: new research directions at Frankfurt University. Storicamente, 11 (1): DOI:10.12977/stor594

Sax, B. (2017). E-Portfolios and the College Community: Towards a New Model of the Online Classroom. E-mentor, 2(69), 82-86. DOI: 10.15219/em69.1295

Shin, J., \& Lee, S. (2015). Evolution of research universities as a national research system in Korea: accomplishments and challenges. Higher Education (00181560), 70 (2): 187-202. DOI:10.1007/s10734-014-9847-5

Skala, A. (2016). Statement on the First Research on Digital Startups in Poland. Przedsiębiorczość Międzynarodowa, 2: 191-202.

Sparks, H., Collins, F.L., \& Kearns, R. (2016). Reflecting on the risks and ethical dilemmas of digital research. Geoforum, 77: 40-46. DOI:10.1016/j.geoforum.2016.09.019

Stensaker, B., Bilbow, G.T., Breslow, L., \& Van Der Vaart, R. (2017). Strengthening Teaching and Learning in Research Universities : Strategies and Initiatives for Institutional Change. Cham: Palgrave Macmillan.

Tsatsou, P. (2016). Digital technologies in the research process: Lessons from the digital research community in the UK. Computers In Human Behavior, 61: 597-608. DOI:10.1016/j.chb.2016.03.053

Yan, W., \& Zhang, Y. (2018). Regular article: Research universities on the ResearchGate social networking site: An examination of institutional differences, research activity level, and social networks formed. Journal of Informetrics, 12: 385-400. DOI:10.1016/j.joi.2017.08.002 